\title{
Editorial
}

\section{DOI: ÍNDICE DE CALIDAD EN LAS REVISTAS DE EDICIONES UNIVERSIDAD DE SALAMANCA}

\author{
DOI: Index Quality Journals of Salamanca University Press
}

\author{
Ángel Luis HERNÁNDEZ-REDERO \\ Universidad de Salamanca. Ediciones Universidad de Salamanca. Edición Digital. Salamanca. España. \\ http://orcid.org/0000-0002-7222-210X \\ Correspondencia: redero@usal.es
}

Fecha de Publicación: 26 de julio de 2016

Conflicto de intereses: Los autores declaran no tener conflictos de intereses Imágenes: Los autores declaran haber obtenido las imágenes con el permiso de los pacientes Política de derechos y autoarchivo: se permite el autoarchivo de la versión post-print (SHERPA/RoMEO) Licencia CC BY-NC-ND. Licencia Creative Commons Atribución-NoComercial-SinDerivar 4.0 Internacional (C) Universidad de Salamanca. Su comercialización está sujeta al permiso del editor

El pasado mes de junio fuimos invitados a participar en las «VI Jornadas-Taller de formación sobre libro electrónico UNE 2016» (Madrid, 6 y 7 de junio), donde disertamos sobre los beneficios del uso editorial del DOI (Digital Object Identifier), en nuestro caso empleado, por el momento, en revistas científicas [1].

En Ediciones Universidad de Salamanca somos unos recién llegados al DOI. Otras editoriales universitarias o institucionales nos podrían ilustrar mucho mejor que nosotros sobre los beneficios de uso del DOI.

CSIC (desde 2008 ha registrado 30 revistas), el Instituto de Salud Carlos III (2009, con 31) -colección SciELO España-, las universidades Politécnica de Valencia (2009, con 6), Complutense de Madrid (2010, con 68), Murcia (2011, con 4) o la Jaume I de Castell (2011, con 10). Otras instituciones están tam- bién presentes, aunque sólo han inscrito alguna publicación aislada, como la Universidad de Huelva (2009), el Centro de Investigaciones Sociológicas (2010), las universidades de Málaga (2010), La Rioja (2010), el INIA (2011), la UNED (2011), las universidades Autónoma de Barcelona (2011), Oberta de Catalunya (2012), Valencia (2012) o Alicante (2012) [2].

\section{DEFINICIÓN DE DOI}

EI DOI es un «identificador único y permanente para las publicaciones electrónicas». Incorporado a la referencia bibliográfica es inalterable y nunca cambia, no así las URL que, tradicionalmente, se venían incluyendo en las referencias bibliográficas.

Se creó en 1997 a iniciativa de editores de contenidos científicos digitales y, en 1998, pasó a ser gestionado por la International 
DOI Foundation, para facilitar el reconocimiento de la propiedad intelectual de los recursos electrónicos.

Se emplea para identificar e-artículos, e-capítulos, e-actas...

Regulado según norma ISO 26324 de 2012, se trata de un código alfanumérico articulado en [3, 4]:

- Un prefijo, que identifica el editor $($ EUSAL = 10.14201).

- Un sufijo, que identifica el objeto digital.

Tiene una estructura variable que, en "eUSAL Revistas», hemos acordado establecer el siguiente patrón:

1. Para los artículos ya publicados en pdf: siglas de la revista + año + vol. + n. ${ }^{\circ}+$ primera pág. + última pág. Ejemplo:

http://dx.doi.org/10.14201/alh201571 1736.

2. Para los artículos en prensa (half of print / preprint): siglas de la revista + año + vol. + n. ${ }^{\circ}+$ ID_OJS. Ejemplo: http://dx.doi.org/10.14201/orl201672. 13998.

Se puede consultar en:

- Directorio específico para consulta del bibliografía con DOI: http://dx.doi.org.

- Genéricamente en cualquier buscador de internet (Google, Yahoo!, Bing, etc.) [5].

\section{AgENCIAS DE REGISTRO DE DOI}

La función principal de las agencias de registro es proporcionar distintos servicios a los editores solicitantes -la asignación del prefijo del DOI, el registro de nombres de DOI, así como proporcionar la infraestructura telemática necesaria para permitir a los editores el registro de los metadatos, etc.Hay unas cuantas agencias - Airiti, China National Knowledge Infrastructure (CNKI), DataCite, EIDR (Entertainment Identifier Registry), ISTIC (The Institute of Scientific and Technical Information of China), JaLC (Japan Link Center), Korea Institute of Science and Technology Information (KISTI), mEDRA (Multilingual European DOI Registration Agency), OP (Publications Office of the European Union)- [6].

EUSAL finalmente eligió Crossref por simplicidad y su infraestructura telemática.
VENTAJAS DE DOI

Las ventajas del uso del DOI son básicamente tres:

1. Las intrínsecas a la propia naturaleza del DOI:

- Es persistente y estable para su localización en la red, aunque cambie la ubicación del objeto digital (puede cambiar la URL o dirección web, pero el DOI permanece inalterable, siempre se localiza).

- Genera un aumento en la visibilidad de una publicación científica y su impacto.

- Es una garantía de «(C copyright» o "CC Creative Commons» de un objeto digital.

- La interoperabilidad con otras plataformas o repositorios de contenido al trabajar con metadatos semánticos XLM.

2. Curriculares de los autores que publican en nuestras revistas digitales cuyo ánimo es el prestigio social:

- $\quad$ ANECA / CNEAI lo tienen presente. En los formularios de la ANECA aparece este campo. No es un campo obligatorio (pero sí se tiene en cuenta una publicación que tenga DOI respecto a la que no lo posea) [7].

- También se considera en el caso de la CNEAI, pero con restricciones: «Todas las aportaciones deberán estar publicadas en los años que se someten a evaluación. La existencia de un identificador DOI (Digital Object Identifier) asociado a una publicación, no significa que el artículo esté ya publicado en un volumen de una revista; podría estar pendiente de publicación y publicarse un año después del último año del tramo que se somete a evaluación» [8].

3. De mejora en la calidad editorial: es uno más de los indicadores de calidad que sí son considerados para el ingreso en según qué bases de datos (Thomson-ISI, Spocus, IRHIM plus, REDIB, Latindex, etc.) [9]. 
NUESTRA EXPERIENCIA EN «EUSAL REVISTAS» Actualmente nos encontramos en un momento de mejora continua de los procesos editoriales con el horizonte en el "Octavo Centenario de la Universidad de Salamanca».

Desde 2009 editamos 22 revistas activas en «eUSAL Revistas» (sistema de gestión OJS).

El 11 de junio de 2013, solicitamos el ingreso en la PILA (The Publishers International Linking Association, Inc.) como paso previo para la concesión del prefijo DOI necesario para formar parte de Crossref, entidad sin ánimo de lucro que los gestiona.

Ya el 27 de enero de 2014, asignamos los primeros DOI en la revista América Latina Hoy.

Actualmente, editamos 30 volúmenes (50 números/año) de revistas y en crecimiento con tan solo dos editores técnicos.

De ellas a 10 se le asignan DOI: dos son de informática y ciencias de la salud y ocho son de ciencias sociales y humanidades (como no podía ser de otro modo, observando el catálogo de EUSAL y la actividad docente de la USAL).

Con nuestra tradición editorial ya cumplíamos con los índices de calidad en las revistas impresas. En 1995, EUSAL encargó un informe al que ahora es el grupo de investigación EC3 de la Facultad de Biblioteconomía de la Universidad de Granada [10]. A partir de entonces en la editorial se ha seguido el proceso de mejora introduciendo el resto de indicaciones considerados en España o en el resto del mundo [11].

Desde el 2008, estudiamos su implantación pero en 2013, por la insistencia de determinadas secretarías de redacción, incorporamos definitivamente el DOI a nuestras revistas.

De todas ellas, el elemento discriminador fue:

- estar en posesión de sello de calidad FECYT;

- $\quad$ o bien, presentes en bases de datos (SCI, Scopus, etc.);

- $\mathrm{O}$ en cuartiles superiores, índices $\mathrm{H}$, etc.
Con esta motivación, actuamos en las secretarías de redacción que se esfuerzan en la mejora continua con el fin de aumentar el impacto y visibilidad de la revista, costeándoles los gastos fijos del DOI y la corrección ortotipográfica.

\section{¿MÉTRICAS ALTERNATIVAS?}

Los editores tenemos datos (pero no tiempo) para estudiar la correlación entre los índices de descarga y el uso del DOI que, como veremos a continuación, demuestran el ascenso en el número de descargas. Esta medición ¿podría ser otra fuente de métricas alternativas?

Para la edición científica, el uso del DOI es un beneficio claro. Un ejemplo evidente es la observación en bruto de los datos de la revista América Latina Hoy (Figura 1).

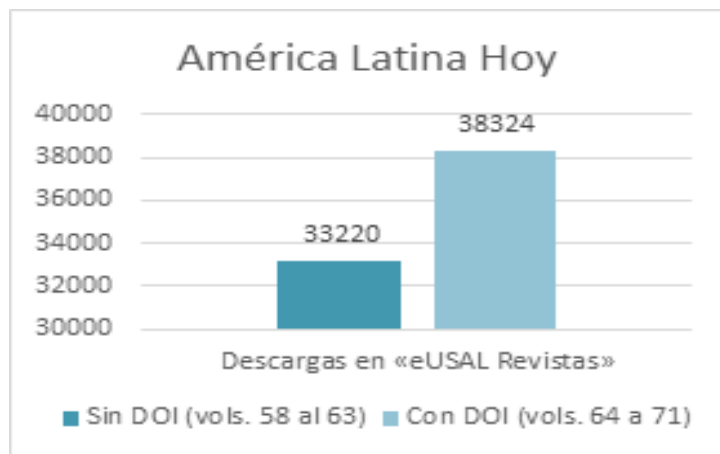

Figura 1. Descargas de América Latina Hoy.

En el gráfico se constata una diferencia de 5104 descargas a favor de los artículos que tienen DOI. Los artículos, sin DOI, llevaban 4 años a disposición de los lectores (entre 2011 y 2013). Los artículos con DOI, llevaban solo 2 años disposición de los lectores (entre 2013 y 2015). Si incluimos el factor tiempo obviamente los artículos más descargados serían a los que asignamos DOI.

A su vez los artículos (con DOI o sin él), están inmediatamente presentes en otra fuente de descargas: el repositorio institucional Gredos. Estas descargas no se han computado. 
TRABAJO DE POSTPRODUCCIÓN

Una vez cerrada la producción y que el número ya está a disposición de los lectores, hay que hacer varias tareas:

1. Hay que exportar los metadatos de OJS con las sintaxis concreta de Crossref / XML. Para ello tendremos que ir a las opciones de OJS: Inicio > Usuario/a > Gestor/a de la revista > Importar/exportar datos > Conector de exportación Crossref XML.

1.1. Los exportaremos mediante la opción «Conector de exportación Crossref XML: Exportar los metadatos del artículo en formato Crossref $X M L$ ». A su vez, la opción permite la de exportación de metadatos de «número completo» o de "artículos» concretos. En EUSAL elegimos aquellos "artículos» a los que les otorgamos DOI. En líneas generales corresponden a las secciones de artículos. Quedan excluidos los índices (en español e inglés), los sumarios analíticos (en español e inglés), habitualmente la sección presentación, y las reseñas/recensiones, etc.

1.2. Finalmente se descarga un fichero XML con la estructura correcta para la posterior importación al Crossref.

2. A continuación importamos los metadatos en Crossref.

2.1. Previamente a esto, hay que chequear los metadatos. Para esto, Crossref tiene una página diseñada exclusivamente para esta función a la que solamente tiene acceso la editorial registrada.

2.2. Si en el chequeo previo no nos ha dado errores, importamos estos metadatos. Para ello accedemos a un área restringida a editores.

3. Por último procedemos a depositar la bibliografía en Crossref. Desde 2010 este servicio es de uso exclusivo de los editores afiliados o mails autorizados previamente por la editorial. Su uso es extremadamente sencillo: se «copipastea» la bibliografía que el autor haya facilitado según las normas de cita empleadas por la revista. Devuelve las referencias bibliográficas en tiempo real con DOI y optativamente con los identificadores de PubMed.

Por último aprovechamos y efectuamos otras tareas complementarias, como pueden ser: metadatos xml preferentemente con destino al repositorio institucional de la USAL/Gredos, y a bases de datos para posicionar las revistas entre ellos Proques, Elsevier, Ebsco, etc.

\section{FINALMENTE}

En la presentación de Revista $O R L$ el 12 de abril de 2016, Juan Luis Gómez _Presidente de la Sociedad Otorrinolaringológica de Castilla y León, Cantabria y La Riojaempleando un símil futbolístico manifestó que «pasamos de jugar en tercera regional a primera división», o a un punto del ascenso al hacernos cargo de la edición de la revista que ya venía editándose de forma amateur.

Nuestro apoyo consiste en la preocupación por la implantación de elementos constatables de calidad editorial (entre otros muchos, el DOI) como reto para «dar un salto, tanto en visibilidad como difusión e internacionalización» [12].

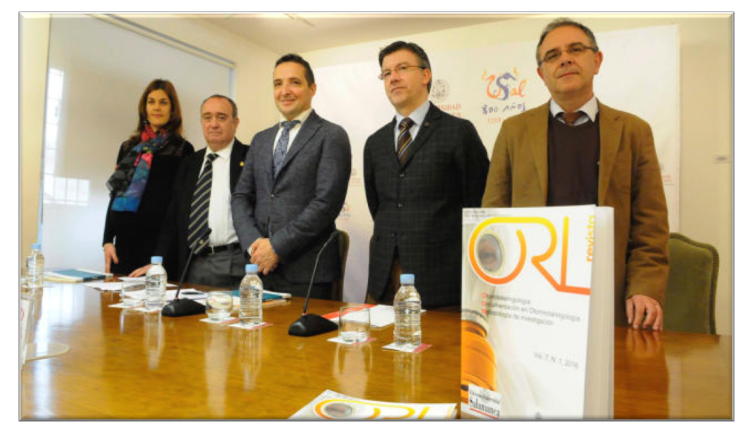

Presentación de Revista ORL y FarmaJournal. Fuente Ical. 
BIBLIOGRAFÍA

1. Redero Á. «DOI: índice de calidad en las revistas de Ediciones Universidad de Salamanca,» 0706 2016. [En línea]. Disponible en: http://www.une.es/media/Ou1/Image/webjunio2016/16_- Ángel Redero.pdf. [Último acceso: 0707 2016].

2. Rodríguez-Yunta L. «Pensando en digital: uso del DOI en revistas españolas, una asignatura aún pendiente,» Anuario ThinkEPI, vol. 7, pp. 164-168, 2013.

3. Alonso Arévalo J. «Crossref» 27 abril 2016. [En línea]. Disponible en: https://www.slideshare.net/mobile/jalonsoarevalo/4-resolvers1. [Último acceso: 7 7 2016].

4. Servicio de Bibliotecas y Documentación, Universidad de Valencia, «EI DOI: qué es y cómo solicitarlo,» [En línea]. Disponible en: http://www.uv.es/uvweb/servei-biblioteques-documentacio/es/serveis/suportinvestigacio-edicio-cientifica/Doi1285872506739.html. [Último acceso: 07 07 2016].

5. Biblioteca de la Universidad de Las Palmas de Gran Canaria, «Apoyo a la investigación,» 2507 2015. [En línea]. Disponible en: http://biblioteca.ulpgc.es/doi. [Último acceso: 0707 2016].

6. International DOI Foundation, «DOI Registration Agencies,» 0501 2016. [En línea]. Disponible en: http://www.doi.org/registration_agencies.html. [Último acceso: 0707 2016].

7. Valenzuela M, García Carreño M, MoyaOrozco V. «Solicitud de Sexenios 20152016 (CNEAl)» [En línea]. Disponible en: http://www.slideshare.net/vicmoyoro/solicitud-de-sexenios-20152016-cneai-paraeducacin-y-psicologa. [Último acceso: 07 07 2016].

8. Resolución de 26 de noviembre de 2015 , de la Comisión Nacional Evaluadora de la Actividad Investigadora, por la que se publican los criterios específicos aprobados para cada uno de los campos de evaluación, 2015.

9. Abadal E, Rius Alcaraz L. «Revistas científicas de las universidades españolas: acciones básicas para aumentar su difusión e impacto,» Revista española de Documentación Científica, vol. 32 , n. ${ }^{\circ} 2$, pp. 240-260, 2008.

10. Ruiz Pérez R, Delgado López-Cózar E, Moneda M, Ruiz de Osma E, Jimenez Contreras E. «Evaluación normativa de la revistas editadas por la Universidad de Salamanca y proyecto para su difusión en bases de datos nacionales e internacionales: Informe (Encargado por Ediciones Universidad de Salamanca)» Grupo de Trabajo sobre Evaluación y Transferencia de la Producción Científica. Universidad de Granada. Facultad de Biblioteconomía y Documentación, Granada, 1995.

11. Delgado López-Cózar E, Ruiz-Pérez R, Jiménez-Contreras $E$. La edición de revistas científicas: Directrices, criterios y modelos de evaluación, Madrid: FECYT, 2006.

12. ICAL y L. G., «La Universidad edita dos revistas científicas para las áreas de Farmacia y Otorrinolaringología,» La Gaceta Regional de Salamanca, 12-04-2016. 